\title{
European League Against Rheumatism (EULAR) recommendations for the management of psoriatic arthritis with pharmacological therapies: 2015 update
}

\author{
L Gossec, ${ }^{1,2}$ J S Smolen, ${ }^{3,4}$ S Ramiro, ${ }^{5} \mathrm{M}$ de Wit, ${ }^{6} \mathrm{M}$ Cutolo, ${ }^{7} \mathrm{M}$ Dougados, ${ }^{8,9}$ \\ P Emery, ${ }^{10,11} \mathrm{R}$ Landewé, ${ }^{12,13} \mathrm{~S}$ Oliver, $^{14} \mathrm{D}$ Aletaha $^{3}{ }^{3} \mathrm{~N}$ Betteridge, ${ }^{6} \mathrm{~J}$ Braun, ${ }^{15}$ \\ G Burmester, ${ }^{16} \mathrm{~J} D$ Cañete, ${ }^{17} \mathrm{~N}$ Damjanov, ${ }^{18}$ O FitzGerald, ${ }^{19} \mathrm{E}^{1}$ Haglund, ${ }^{20,21}$ \\ P Helliwell, ${ }^{22} \mathrm{~T}$ K Kvien, ${ }^{23} \mathrm{R}$ Lories, $^{24,25} \mathrm{~T}^{2}$ Luger, ${ }^{26}$ M Maccarone, ${ }^{27}$ \\ H Marzo-Ortega, ${ }^{10,11}$ D McGonagle, ${ }^{10,11}$ I B Mclnnes, ${ }^{28}$ I Olivieri, ${ }^{29} \mathrm{~K}$ Pavelka, $^{30}$ \\ G Schett, ${ }^{31}$ J Sieper, $^{32}$ F van den Bosch, ${ }^{33}$ D J Veale, ${ }^{34}$ J Wollenhaupt, $^{35}$ A Zink, $^{36}$ \\ D van der Heijde
}

For numbered affiliations see end of article.

\section{Correspondence to} Professor Laure Gossec, Hôpital Pitié-Salpétrière, Service de Rhumatologie, 47-83, boulevard de l'Hôpital, Paris 75013, France; laure.gossec@aphp.fr

LG and JSS contributed equally.

Received 30 July 2015 Revised 7 October 2015 Accepted 30 October 2015 Published Online First 7 December 2015

\section{Linked}

http://dx.doi.org/10.1136/ annrheumdis-2015-208466

\footnotetext{
To cite: Gossec $L_{\text {, }}$

Smolen JS, Ramiro S, et al. Ann Rheum Dis

2016:75:499-510.
}

\section{ABSTRACT}

Background Since the publication of the European League Against Rheumatism recommendations for the pharmacological treatment of psoriatic arthritis (PsA) in 2012, new evidence and new therapeutic agents have emerged. The objective was to update these recommendations.

Methods A systematic literature review was performed regarding pharmacological treatment in PSA.

Subsequently, recommendations were formulated based on the evidence and the expert opinion of the 34 Task Force members. Levels of evidence and strengths of recommendations were allocated.

Results The updated recommendations comprise 5 overarching principles and 10 recommendations, covering pharmacological therapies for PsA from non-steroidal anti-inflammatory drugs (NSAIDs), to conventional synthetic (csDMARD) and biological (bDMARD) disease-modifying antirheumatic drugs, whatever their mode of action, taking articular and extra-articular manifestations of PsA into account, but focusing on musculoskeletal involvement. The overarching principles address the need for shared decision-making and treatment objectives. The recommendations address csDMARDs as an initial therapy after failure of NSAIDs and local therapy for active disease, followed, if necessary, by a bDMARD or a targeted synthetic DMARD (tsDMARD). The first bDMARD would usually be a tumour necrosis factor (TNF) inhibitor. bDMARDs targeting interleukin (IL)12/23 (ustekinumab) or IL-17 pathways (secukinumab) may be used in patients for whom TNF inhibitors are inappropriate and a tsDMARD such as a phosphodiesterase 4-inhibitor (apremilast) if bDMARDs are inappropriate. If the first bDMARD strategy fails, any other bDMARD or tsDMARD may be used.

Conclusions These recommendations provide stakeholders with an updated consensus on the pharmacological treatment of PsA and strategies to reach optimal outcomes in PsA, based on a combination of evidence and expert opinion.

\section{INTRODUCTION}

The management of psoriatic arthritis (PsA) rests on non-pharmacological and pharmacological measures. The so-called disease-modifying antirheumatic drugs (DMARDs) are commonly characterised by their capacity to reduce or reverse signs and symptoms, disability, impairment of quality of life, inability to work and progression of joint damage and thus can interfere with the entire disease process. ${ }^{12}$ There are three major classes of DMARDs, loosely grouped according to different mechanisms of action: conventional synthetic (cs) DMARDs such as methotrexate (MTX), sulfasalazine and leflunomide; biological agents (bDMARDs) and targeted synthetic (ts) DMARDs, such as phosphodiesterase (PDE) inhibitors or JAK-inhibitors such as tofacitinib. ${ }^{3}$ Tumour necrosis factor inhibitors (TNFis) have been shown to be efficacious in PsA. ${ }^{4}$ In contrast with rheumatoid arthritis (RA), until recently only TNFis were available as therapeutic agents in PsA, if csDMARDs failed to exhibit efficacy. Recently however, novel therapies with utility in PsA have emerged. PsA is heterogeneous by virtue of its broad phenotypes of musculoskeletal involvement (peripheral arthritis, dactylitis, enthesitis and axial disease), and its spectrum of extra-articular manifestations, especially skin and nails, and other organ involvement. ${ }^{5-7}$ csDMARDs and bDMARDs have differential effects on the various disease manifestations.

With several therapeutic options available and insufficient information on differential efficacy and safety, treatment decisions in clinical practice remain challenging. Therefore, the European League Against Rheumatism (EULAR) developed recommendations for the management of PsA with these drugs in 2011. ${ }^{8}$ These recommendations were based on two systematic literature reviews $(\mathrm{SLRs})^{4}$ and focused on indications for the use of and suggestions for differential and strategic employment of csDMARDs and bDMARDs based on treatment targets and disease risk assessment, 
also making clear that safety aspects and contraindications need to be considered in therapeutic decision-making. As an umbrella organisation of national rheumatological societies, EULAR decided to put its primary emphasis on the musculoskeletal aspects of the disease. ${ }^{8}$ The EULAR recommendations were based on the evidence available at that time ${ }^{4}$ and on the results of the discussions and votes by an expert committee. However, as with most recommendations and especially in a rapidly evolving field such as PsA, it was anticipated that the 2012 recommendations would need updating within a few years. Indeed, additional evidence on agents already approved at that time as well as data on new compounds have become available since 2012 (S Ramiro, JS Smolen, S Landewé, et al, Pharmacological treatment of psoriatic arthritis: a systematic literature review for the 2015 update of the EULAR Recommendations for the management of psoriatic arthritis. Submitted to ARD 2015). ${ }^{9}$ Moreover, new trials have addressed therapeutic strategies ${ }^{10}$ and treat-to-target recommendations have been developed for PsA since the publication of the EULAR PsA management recommendations. ${ }^{1112}$ All these developments prompted us to update the recommendations for the management of PsA with nontopical pharmacological therapies.

\section{METHODS}

The EULAR standardised operating procedures were applied. ${ }^{13}$ In June 2014, a Steering Group consisting of seven rheumatologists, one fellow, one patient research partner and one health professional defined the questions that were to be addressed through an SLR. The SLR was performed between June 2014 and January 2015 and is published as an accompanying paper. ${ }^{14}$ In parallel, a general review of treatment strategies, prognostic factors and comorbidities was performed. In January 2015, the Steering Group as well as the Task Force met to discuss the results of the literature review, aiming at aggregating the available information on disease management in PsA into practical recommendations. The Task Force consisted of 34 persons from 14 European countries: 27 rheumatologists, 3 people affected with PsA, 2 health professionals, 1 dermatologist and 1 rheumatology fellow. This inclusive approach aimed at obtaining broad consensus and applicability of the recommendations.

The process was evidence-based and consensus-based and included, between June 2014 and February 2015, two expert meetings, the SLR and extensive discussions. The recently proposed nomenclature distinguishing csDMARDs, tsDMARDs, bDMARDs, biologic original DMARDs and biosimilar DMARDs (bsDMARDs) was applied. ${ }^{3}$

Each recommendation from 2012 as well as those that were newly developed based on the SLR were discussed in detail and, where necessary, modified until acceptable to the Task Force; at each step, a $67 \%$ majority was required for approval or rejection of a particular recommendation. If a clear-cut approval or rejection was not obtained, the wording was amended until it met the predetermined level of approval. Thus, each of the recommendations presented here has received approval by at least two-thirds of the Task Force members. The Task Force members were provided with the category of evidence and grade of recommendation for each item. $^{15} 16$

After the final meeting, an anonymised email-based voting on the level of agreement was performed, using a $0-10$ scale with a vote of 0 meaning total disagreement with a particular recommendation and 10 meaning total agreement with it. The means and SDs of scores from the whole group were calculated.
The recommendations are targeted at all appropriate stakeholders: (A) first, physicians, aiming particularly at rheumatologists, but also other physicians involved in the care of people with PsA (irrespective of clinical presentation), including general practitioners, dermatologists and other specialists; (B) people with PsA who can use these recommendations for information on current therapies, treatment strategies and opportunities; and (C) other stakeholders which include officials in governments, social security agencies and reimbursement agencies as well as hospital managers.

\section{RESULTS}

\section{Overarching principles}

The Task Force designated some principles regarding the care of patients with PsA of such generic nature as to be 'overarching' (table 1).

The first and third overarching principles remain unchanged compared with 2012. Of note, an optimal management of patients with PsA also includes non-pharmacological strategies with patient education and regular exercising. In the second overarching principle, the 'shared decision' with the patient, which refers to the necessity to discuss and record treatment aims, management plans and reasons for the recommended approaches with the patient, was expanded by adding 'considering efficacy, safety and costs'. All these aspects, including costs, need to be taken into account when making treatment decisions. Indeed, while rheumatologists and patients cannot be held responsible for costs of therapies, they need to bear in mind that cost considerations are part of evidence-based medicine approaches, ${ }^{17}$ especially also in the light of the advent of novel targeted therapies and biosimilars (see below).

In the fourth overarching principle, the reference to the treatment target as remission has been deleted, since it is now dealt with in Recommendation 1, but the necessity to abrogate inflammation, which may be seen as a surrogate wording for the term remission, is still clearly stated.

The fifth overarching principle has been modified: formerly it dealt with the principle of treating to target, but this is now contained in Recommendation 1. This principle now mentions the importance of considering comorbidities, which are frequent in PsA and need to be assessed and treated. In particular, cardiovascular diseases and metabolic syndrome appear more common in patients with PsA than in controls. ${ }^{18} 19$

\section{Recommendations}

Beyond the overarching principles, the process led to 10 recommendations on drug management and treatment strategies, presented in table 1 . Table 1 also provides the category of evidence, grade of recommendation and level of agreement for each of the bullet points. ${ }^{16}$ These recommendations also serve as the basis for the algorithm provided in figure 1.

Importantly, the table and the figure synthesise the rationale behind the recommendations in an abbreviated way that may not fully reflect all important aspects. Therefore the accompanying text, presented below, has to be regarded as integral to the recommendations; the multiple facets are contained within the text and not necessarily within the bullet points in the table let alone the algorithm. Furthermore, in all cases the balance between efficacy and safety must be taken into account for an individual patient.

1. Treatment should be aimed at reaching the target of remission or, alternatively, minimal/low disease activity, by regular monitoring and appropriate adjustment of therapy. 
Table 1 Updated EULAR recommendations for the management of PsA, with levels of evidence, grade of recommendations and level of agreement

Overarching principles

Level of agreement $($ mean \pm SD)

A. PsA is a heterogeneous and potentially severe disease, which may require multidisciplinary treatment $9.6 \pm 1.1$

B. Treatment of patients with PsA should aim at the best care and must be based on a shared decision $9.2 \pm 1.7$ between the patient and the rheumatologist, considering efficacy, safety and costs

C. Rheumatologists are the specialists who should primarily care for the musculoskeletal manifestations of patients with PsA; in the presence of clinically significant skin involvement a rheumatologist and a dermatologist should collaborate in diagnosis and management

D. The primary goal of treating patients with PsA is to maximise health-related quality of life, through control of symptoms, prevention of structural damage, normalisation of function and social participation; abrogation of inflammation is an important component to achieve these goals

E. When managing patients with PsA, extra-articular manifestations, metabolic syndrome, cardiovascular disease and other comorbidities should be taken into account

\section{Recommendations}

1. Treatment should be aimed at reaching the target of remission or, alternatively, minimal/low disease activity, by regular monitoring and appropriate adjustment of therapy

2. In patients with PsA, NSAIDs may be used to relieve musculoskeletal signs and symptoms

3. In patients with peripheral arthritis, particularly in those with many swollen joints, structural damage in the presence of inflammation, high ESR/CRP and/or clinically relevant extra-articular manifestations ${ }^{a}$, csDMARDs should be considered ${ }^{b}$ at an early stage ${ }^{a}$, with methotrexate preferred in those with relevant skin involvement ${ }^{b}$

4. Local injections of glucocorticoids should be considered as adjunctive therapy in PsA ${ }^{\text {a }}$; systemic glucocorticoids may be used with caution at the lowest effective dose ${ }^{b}$

5. In patients with peripheral arthritis and an inadequate response to at least one cSDMARD, therapy with a bDMARD, usually a TNF inhibitor, should be commenced

6. In patients with peripheral arthritis and an inadequate response to at least one CSDMARD, in whom TNF inhibitors are not appropriate, bDMARDs targeting IL12/23 or IL17 pathways may be considered

7. In patients with peripheral arthritis and an inadequate response to at least one csDMARD, in whom bDMARDs are not appropriate, a targeted synthetic DMARD such as a PDE4-inhibitor may be considered

8. In patients with active enthesitis and/or dactylitis and insufficient response to NSAIDs or local glucocorticoid injections, therapy with a bDMARD should be considered, which according to current practice is a TNF inhibitor

9. In patients with predominantly axial disease that is active and has insufficient response to NSAIDs, therapy with a bDMARD should be considered, which according to current practice is a TNF inhibitor

10. In patients who fail to respond adequately to a bDMARD, switching to another bDMARD should be considered, including switching between TNF inhibitors

$\begin{aligned} & \text { Level of agreement } \\ & (\text { mean } \pm \text { SD) }\end{aligned}$
$9.6 \pm 1.1$
$9.2 \pm 1.7$
$9.5 \pm 0.8$

$9.6 \pm 1.0$

\begin{tabular}{lll}
$\begin{array}{l}\text { Level of } \\
\text { evidence }\end{array}$ & $\begin{array}{l}\text { Grade of } \\
\text { recommendation }\end{array}$ & $\begin{array}{l}\text { Level of agreement } \\
\text { (mean } \pm \text { SD }\end{array}$ \\
\hline 1b & A & $9.6 \pm 0.9$ \\
\hline 1b & A & $9.6 \pm 0.8$ \\
\hline $\begin{array}{l}\text { a: } 3 \\
\text { b: } 1 \mathrm{~b}\end{array}$ & B & $9.4 \pm 0.8$ \\
\hline
\end{tabular}

$\begin{array}{lll}\begin{array}{l}\mathrm{a}: 3 \mathrm{~b} \\ \mathrm{~b}: 4\end{array} & \mathrm{C} & 9.1 \pm 1.2 \\ 1 \mathrm{~b} & \text { B } & 9.5 \pm 0.7 \\ 1 \mathrm{~b} & \text { B } & 9.1 \pm 1.1 \\ 1 \mathrm{~b} & \text { B } & 8.5 \pm 1.4\end{array}$

1b $\quad$ B $9.1 \pm 1.2$

The level of evidence was determined for different parts of the recommendation (referred to as a and $b$ ) where necessary.

The level of agreement was computed as a $0-10$ scale.

bDMARD, biological DMARD; CRP, C reactive protein; CSDMARDs, conventional synthetic disease-modifying antirheumatic drugs, such as methotrexate, sulfasalazine or leflunomide; ESR, erythrocyte sedimentation rate; EULAR, European League Against Rheumatism; NSAIDs, non-steroidal anti-inflammatory drugs; PDE, phosphodiesterase; PsA, psoriatic arthritis; TNF, tumour necrosis factor.

This recommendation is new and comprises previous overarching principle $\mathrm{E}$ and Recommendation 2, but also elements of previous overarching principle D. ${ }^{8}$ Targeting an optimal outcome by adjusting treatment in the context of regular disease activity monitoring was deemed so important, that this recommendation was placed as number 1 , especially given its general strategic nature.

In RA, attaining a state of remission or low disease activity leads to better structural and functional outcomes than allowing moderate, let alone high, disease activity. ${ }^{2021}$ In PsA, there exist few data regarding natural history, treatment objectives and remission. ${ }^{11} 22-25$ However since in PsA inflammation is related to long-term outcomes of joint involvement, ${ }^{26-30}$ this recommendation states that the objective in patients with PsA is remission or if remission cannot be achieved, a low or minimal disease activity state. Remission is defined here as the absence of clinical and laboratory evidence of significant inflammatory disease activity. ${ }^{11}$ In addition to absence of inflammation in the joints, absence of enthesitis and dactylitis are also important.
It should be noted that this remission of inflammation may not equate to complete absence of all symptoms for many patients. Indeed, recent work in PsA demonstrated that the impact of the disease on quality of life is related to pain, skin problems and functional disability, and fatigue, as well as emotional and social aspects of impact. ${ }^{31}$ Some of these aspects of impact may be less accessible to pharmacological therapies of PsA, thus leading to a 'residual' impact in the absence of inflammation.

Furthermore, remission may be difficult to achieve in PsA. ${ }^{24}$ 32-34 Factors associated with higher remission rates appear to be younger age, lower functional impairment and higher $\mathrm{C}$ reactive protein levels in some cases. ${ }^{35}$ While in RA stringent remission criteria have been agreed upon and validated as being associated with optimal outcomes, ${ }^{36}$ remission is still insufficiently defined in PsA. ${ }^{11} 37$ We suggest that the use of outcomes where remission/low disease activity have been defined, should be considered. This is now the case for several scores used in PsA, some of which focus only on arthritis whereas others encompass various aspects of psoriatic disease. ${ }^{38}$ 
Figure 1 The EULAR 2015 algorithm for treatment of PsA with pharmacological non-topical treatments. bDMARD, biological DMARD; CSDMARDs, conventional synthetic DMARD; DMARD, disease-modifying antirheumatic drug; Rheumatism; IL, interleukin; MTX, methotrexate; PsA, psoriatic arthritis; $\mathrm{TNFi}$, tumour necrosis factor inhibitor; tsDMARD, targeted synthetic DMARD. EULAR, European League Against

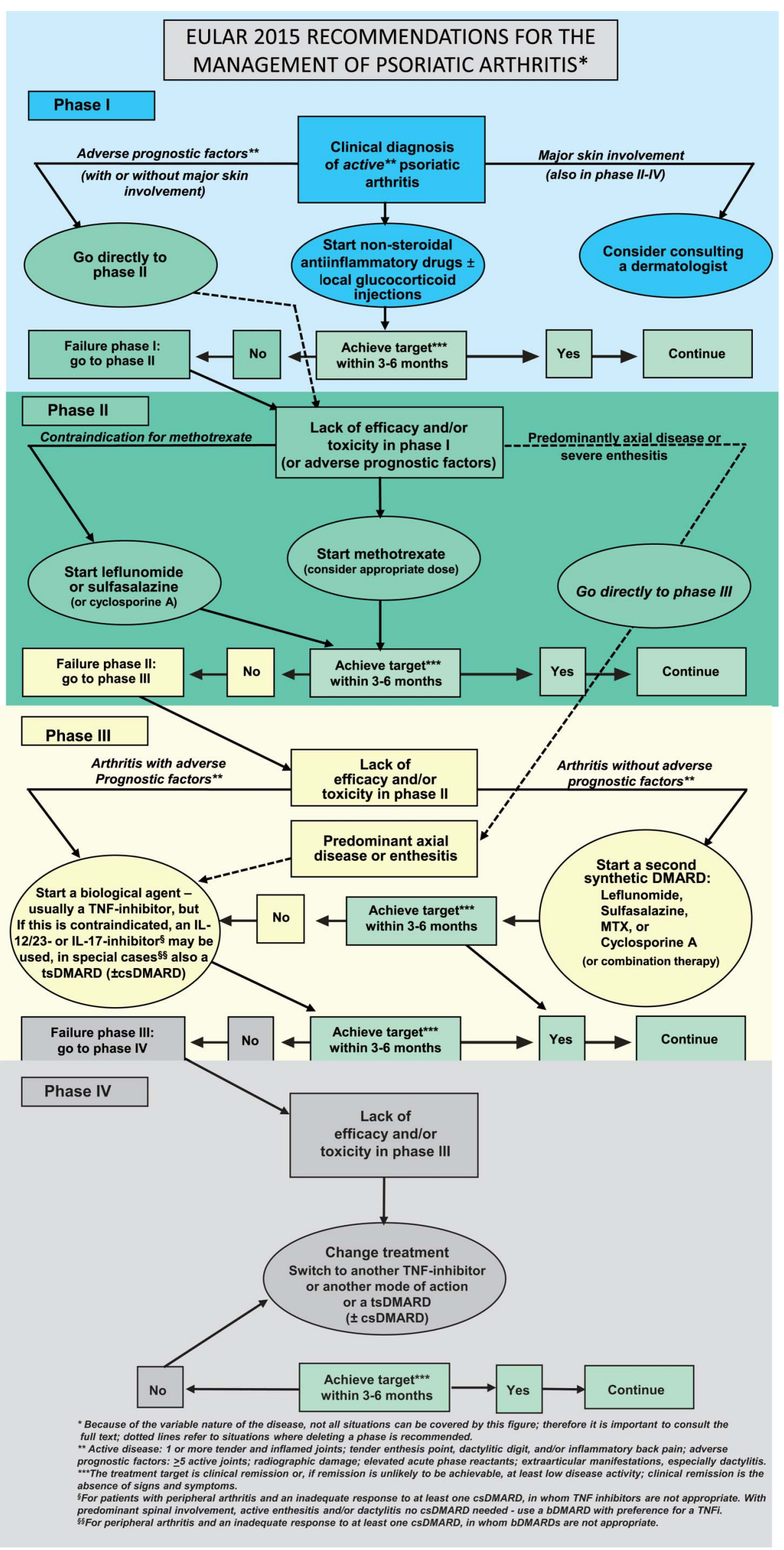


As regards joint involvement, a stringent remission definition and criteria for low disease activity by the Disease Activity index for PSoriatic Arthritis (DAPSA) have been recently defined and validated. ${ }^{25}$ However, minimal/low disease may also be a relevant target especially for long-standing disease, as stringent remission may not be achievable in these patients or in some patients with comorbidities that preclude escalation of therapy. Minimal disease activity in PsA has been defined as five of the seven criteria comprising musculoskeletal and skin manifestations and patient-reported outcomes. ${ }^{39-43}$ This outcome has been shown in one study to be predictive of less structural degradation, and in the recent Tight control in PsA (TICOPA) trial to be a valid treatment target. ${ }^{4}$

Definitions of remission and acceptable residual disease activity levels in PsA, its predictors and its relationship with longterm outcomes are still a part of the research agenda and more thorough assessment of prognostic markers of severity (related to risk of progressive disease, structural damage, physical disability and quality of life) must still be addressed.

This recommendation also addresses monitoring and the principle of 'treating to target' and tight control which have recently been expanded to PsA and updated for RA. ${ }^{11} 12{ }^{20}$ Because of the lack of data regarding the best interval for patient monitoring, the recommendation states 'regular monitoring', but we suggest in usual care patients with active disease should be seen between monthly to every 3 months. Similarly, treatment should be adjusted 'appropriately': more data regarding monitoring and treatment adaptation are needed in PsA. The only randomised trial addressing specifically a tight control approach in PsA is the recently published TICOPA trial. ${ }^{10}{ }^{44}$ In this trial, patients with active PsA randomised to the tight control arm had a treatment escalation starting with csDMARDs up to bDMARDs, if the predefined target of minimal disease activity was not reached: the group with tight control had more favourable outcomes.

The best ways to monitor disease activity in PsA are uncertain. ${ }^{37} 45-48$ The recommended Core Set for PsA comprises peripheral joints, pain, patient global assessment, physical function, quality of life, fatigue and acute phase reactants. ${ }^{45}$ In any case, it is important to use validated and quantified measurements. ${ }^{49}$ The validity of the individual measures has been compared in a recent study. ${ }^{37}$

In clinical practice, although such measures are imperfect, it can be suggested to use composite measures focusing on joint involvement and thus including joint counts, such as the Disease Activity Score or the Simplified Disease Activity Index or the Clinical Disease Activity Index (all originally developed for RA) ${ }^{50}$ the Composite Psoriatic Disease Activity Index; ${ }^{51}$ the DAPSA $;{ }^{52}$ or the Psoriatic ArthritiS Disease Activity Score. ${ }^{38} 53$ These scores have been shown to exhibit partly different discriminative abilities. ${ }^{37}$ However, further work is needed, especially since it is not clear if using a composite measures across disease tissues which may (indeed appear to) have differential therapeutic responses is appropriate.

2. In patients with PsA, non-steroidal anti-inflammatory drugs (NSAIDs) may be used to relieve musculoskeletal signs and symptoms.

This recommendation remains unchanged. NSAIDs have been shown to be efficacious on joint symptoms and especially patients with mild joint disease may benefit from NSAIDs, though there is no demonstrated efficacy on skin lesions and risks and contraindications need to be considered. However, a benefit from NSAIDs should be seen within a few weeks and NSAIDs should not be the only therapy above 3 months if patients have active disease as defined in Recommendation 3.
3. In patients with peripheral arthritis, particularly in those with many swollen joints, structural damage in the presence of inflammation, high erythrocyte sedimentation rate/C reactive protein and/or clinically relevant extra-articular manifestations, csDMARDs should be considered at an early stage, with MTX preferred in those with relevant skin involvement.

This recommendation combines items 2 and 3 of the 2012 recommendations. However, in 2012 the term 'active disease' was used, whereas here it was replaced by 'peripheral arthritis' since this is more precise ('active disease' also meaning potentially active skin disease). As in 2012, the experts considered that patients with peripheral arthritis and poor prognosis should be promptly started on csDMARDs, and also with milder disease if arthritis persisted despite NSAID therapy and despite glucocorticoid injections if indicated. Peripheral arthritis in this context is defined globally as one or more tender and swollen joints.

The natural history of PsA is variable and not well known given the lack of large, long-term cohorts; ${ }^{54}$ thus prognostic factors are still part of the research agenda in PsA. Poor prognostic factors, as agreed upon by the Task Force, are a high number of actively involved joints, either tender or swollen (defined as five or more); radiographic damage (joint destruction), in particular if there is also inflammation; elevated acute phase reactants (ie, any value above the upper limit of normal as serological indication of inflammation); and extra-articular manifestations, in particular dactylitis. ${ }^{26} 285^{55-58}$ The presence of any one factor is sufficient to recommend early csDMARD therapy, but usually more than one will be present in patients with bad prognosis.

The time that can elapse without structural or functional consequence before a csDMARD is started in the presence of active peripheral PsA is unclear. The phrasing 'at an early stage' implies starting treatment within a maximum of 3 months if the PsA is active (in particular with active synovitis), particularly in the presence of the bad prognostic markers mentioned above. There are several recently published studies showing that a prolonged delay before diagnosis and/or before starting a csDMARD is associated with less favourable outcomes. ${ }^{59-63}$ These studies encourage earlier treatment commencement-the question of a 'window of opportunity' in PsA still constitutes an important part of the research agenda.

Based on the available literature (Ramiro $\mathrm{S}$ et al, Submitted to ARD 2015) and similarly to the 2012 recommendations, the experts recommended MTX as the first-choice csDMARD. This decision took into account the relative lack of data from randomised controlled trials, as noted in the 2012 SLR $^{4}$ and the randomised controlled trial of MTX published in 2012 which did not reach the primary end point. ${ }^{64}$ The group was also aware of the lack of demonstration of structural efficacy of MTX. The Task Force however also considered data on the wide use and good treatment maintenance of MTX in PsA. Indeed, MTX maintenance was around $65 \%$ at 2 years in the Norwegian DMARD registry, which appeared similar to its maintenance in RA. ${ }^{65}{ }^{66}$ Moreover, the TICOPA trial revealed that $22 \%$ of treated patients achieved minimal disease activity on MTX alone. ${ }^{44}$ When treating with MTX, careful consideration must be given to the prescription of an efficacious dose which is usually in the $15-25 \mathrm{mg} /$ week range, to the route (subcutaneous or oral) and to folate substitution. ${ }^{67}$

In patients with clinically 'relevant' psoriasis, MTX is specifically mentioned as the preferred option, given its demonstrated efficacy on skin involvement. ${ }^{68}$ Although this recommendation 
does not refer to composite skin indices such as the PASI (which are widely used in trials, but not by rheumatologists in clinical practice), the present criteria for 'clinically relevant' skin psoriasis would correspond, in dermatological terms, to moderate to severe psoriasis, defined as a body surface area involvement $>10 \%$, or more limited psoriasis leading to significant impact on quality of life (eg, face/hand/genital involvement).

There were no new data prompting us to modify our previous recommendation on other csDMARDs including sulfasalazine, leflunomide, ciclosporine (although its use is limited by toxicity issues), and in some cases gold salts and azathioprine, though for these last drugs the level of evidence is low. ${ }^{4}$ Their effect on skin involvement is usually smaller than that of MTX. Although there is little evidence on efficacy of csDMARD combinations, these may be considered. ${ }^{1069}$

4. Local injections of glucocorticoids should be considered as adjunctive therapy in PsA; systemic glucocorticoids may be used with caution at the lowest effective dose.

This recommendation remained unchanged. While no new evidence has accumulated since the last recommendations, we reiterate that intra-articular glucocorticoids may have a place in the treatment of patients with PsA, in particular in patients with monoarthritis/oligoarthritis. ${ }^{70}$ Glucocorticoid injections may also be helpful in dactylitis (tendon sheath injections) and in enthesitis, for example, at the elbow or the retrocalcaneal bursae in Achilles enthesitis. Ultrasound can help guide these injections if needed. The fear of reactivation of psoriasis by glucocorticoids use in the rheumatology setting is not substantiated by evidence, but long-term use of systemic glucocorticoids should be avoided based on the significant risks of adverse events and in particular the adverse event profile of longerterm glucocorticoid therapy needs to be taken into consideration when initiating and especially continuing oral glucocorticoids. ${ }^{7172}$

5. In patients with peripheral arthritis and an inadequate response to at least one csDMARD, therapy with a bDMARD, usually a TNFi, should be commenced.

The meaning of this recommendation remained essentially unchanged though the terminology has been updated and the sole reference to TNFis in 2012 has been expanded to bDMARDs in general, but with a primary focus on TNFi. In contrast to 2012, more biologicals have shown efficacy in PsA, and some have either been approved or are under consideration for approval; this will be dealt with in subsequent recommendations.

In patients with peripheral arthritis in whom a csDMARD (usually MTX because of its effects on joints and skin, but also leflunomide, sulfasalazine or others, see above) is not efficacious (ie, the treatment target of at least low disease activity has not been reached) even though the treatment has been taken for an appropriate length of time (usually 3-6 months), a bDMARD can be considered. Treatment escalation is relevant if the disease is active, that is, if there is evidence of active arthritis in terms of swollen joints and/or at least moderate disease activity by a composite disease activity measure.

The focus on TNFi among the bDMARDs is based here on the opinion of the experts, who felt that given the long-term experience, the well established efficacy/safety balance in PsA, and usual practice, currently TNFi treatment would usually be the first choice. All the available originator TNFis (adalimumab, certolizumab pegol, etanercept, golimumab and infliximab) have demonstrated efficacy in PsA, for skin and joint involvement, as well as in preventing radiographic damage (Ramiro $\mathrm{S}$ et al, Submitted to ARD 2015). ${ }^{4} 73$ Furthermore, TNFis have shown a high retention rate over time in cohort studies. ${ }^{74} 75$ There were no evident differences regarding the efficacy of the different TNFis on the joints, although no head-to-head comparisons exist (Ramiro S et al, Submitted to ARD 2015). ${ }^{4}$ However, for psoriatic skin involvement, it seems that the TNF receptor construct etanercept is less efficacious, or at least has a slower onset, than for the other TNF targeting drugs (although there are, again, no head-to-head comparisons available). Likewise, bsDMARDs of TNFis approved by the European Medical Agency are regarded by the Task Force to be indeed similar to and thus equally applicable as the biological originator TNFis in PsA and psoriasis. Also biosimilar TNFis which are approved by FDA and/or EMA are regarded to be similar to the respective biological originator TNFis. Indeed, a biosimilar infliximab agent has been recently approved by The European Medicine Agency based on studies in RA and ankylosing spondylitis and extrapolated to all other indications for which infliximab has been approved. ${ }^{76}$

Recent data suggest that continuation of a concomitant csDMARD therapy in combination with TNFis is beneficial in PsA in terms of treatment maintenance and levels of response, especially in patients using monoclonal antibodies, but more data are warranted including the effect of concomitant csDMARD on immunogenicity. ${ }^{75} 7778$

Regarding safety, the new data available since the 2012 recommendations were published suggest that bDMARDs have a similar and acceptable risk profile in PsA as in psoriasis or RA. $^{79}$

In the 2012 recommendations, the exceptional use of TNFis in 'a very active patient naïve of disease-modifying treatment' had been addressed in Recommendation 8. This has been deleted in the current recommendations given the lack of data and the lack of consensus and, thus, no longer constitutes a recommendation.

6. In patients with peripheral arthritis and an inadequate response to at least one csDMARD, in whom TNFis are not appropriate, bDMARDs targeting interleukin (IL) 12/23 or IL-17 pathways may be considered.

Drugs with two novel mechanisms of action, namely the IL-12/23 and IL-17 pathways, have recently demonstrated clinically relevant efficacy in PsA (Ramiro $S$ et al, Submitted to ARD 2015). Regarding the IL-12/23 pathway, ustekinumab is currently the bDMARD with most available data; ${ }^{80-84}$ the IL-23 blockers guselkumab and tildrakizumab have to date only been assessed with good efficacy in skin psoriasis. ${ }^{85}{ }^{86}$ Regarding the IL-17 pathway, secukinumab is the drug with most available data. ${ }^{87-89}$ Ixekizumab is currently being tested in PsA whereas brodalumab has shown efficacy, but its development is currently on hold. ${ }^{90}$

The Task Force felt that the place of these new drugs and in particular of the licensed drugs ustekinumab (for psoriasis and PsA) and secukinumab (at the time of the Task Force meeting licensed for psoriasis, not PsA, but with efficacy demonstrated in PsA phase 3 trials) in the treatment algorithm in 2015 should be after an inadequate response to at least one csDMARD (this means: as second-line DMARD). However, it should be kept in mind that both agents have shown less efficacy numerically in patients who had previously received TNFi compared with those who had only failed csDMARDs (see Recommendation 10); this reduced responsiveness is also observed with sequential TNFi use. While the safety profiles of these new agents are not unfavourable, long-term safety data are needed to fully appreciate their benefit:risk profile. Therefore, in light of the efficacy/ safety profile of these drugs, the Task Force felt that these new 
drugs should usually be recommended for patients in whom TNFis may not be appropriate. No particular sequence was recommended between these two new bDMARDs. Further, it is currently not possible to recommend the continuation of a csDMARD with the new bDMARDs, given the lack of evidence for an added benefit from co-medication in the randomised controlled trials (in post hoc analyses), although it is not needed to discontinue csDMARDs and not at all an error to continue them (Ramiro S et al, Submitted to ARD 2015). Elucidation of this question constitutes part of the research agenda.

Patients in whom TNFis may not be appropriate include, for example, patients with comorbidities or those with a history of infections or patients who prefer not to be treated with a TNFi.

7. In patients with peripheral arthritis and an inadequate response to at least one csDMARD, in whom bDMARDs are not appropriate, a tsDMARD, such as a PDE4-inhibitor, may be considered.

Apremilast is a tsDMARD acting as a PDE4-inhibitor and has been demonstrated to be efficacious in PsA (Ramiro $S$ et al, Submitted to ARD 2015). The SLR performed for the current task found a moderate efficacy of apremilast on joints, skin and entheses in PsA. ${ }^{91-93}$ Thus, apremilast is a new drug, which will expand the pharmacopoeia in PsA. Given the moderate effect size of apremilast on most outcomes in PsA, the Task Force discussed at length the position of this drug. Like all agents, the relationship between benefit, risk and costs has to be considered. Taking into account apremilast's relatively low efficacy, not insignificant costs, the lack of structural data and studies comparing it with MTX, other csDMARDs or bDMARDs, and the good overall safety profile, we suggest the place for this drug should at this time in most cases be limited to patients who failed to reach the treatment target on csDMARDs and for whom bDMARDs may not be appropriate. This would include, for example, patients with comorbidities or a history of infections contraindicating any bDMARD. Such a recommendation cannot be considered as based mainly on evidence, as this use was not studied specifically in the large apremilast phase 3 programme, which included mostly patients who were naive to bDMARDs. Thus in some cases apremilast can also be considered earlier in the algorithm, perhaps for patients without markers of severe prognosis or those who explicitly do not wish to receive a parenteral medication; this would however be at the discretion of the physician, as the group did not reach consensus on such a situation. This recommendation received the lowest level of agreement among all bullet points, reflecting the diversity of opinions.

8. In patients with active enthesitis and/or dactylitis and insufficient response to NSAIDs or local glucocorticoid injections, therapy with a bDMARD should be considered, which according to current practice is a TNFi.

This recommendation deals with the subgroup of patients with predominant enthesitis/dactylitis. In this patient population, no data-driven definition of 'active' disease (relative to enthesitis/dactylitis) exists and the Task Force considered at least one active localisation as active disease, taking into account quality of life consequences as most relevant in these patients. In these patients, after failure of local or non-specific antiinflammatory therapy, bDMARDs may be applied even if no csDMARDs have been tried, since the latter have not been proven efficacious in treating these aspects of PsA, especially enthesitis. ${ }^{94} 95$ The experts felt the data did not allow a definitive primary choice between a TNFi or bDMARDs targeting IL-12/23 or IL-17 pathways, since there are no head-to-head comparisons and based on the available data all these agents appear to have similar efficacy on enthesitis and dactylitis.
Comparisons across trials were difficult because different outcome measures are used. However, as stated above, the longest experience exists for TNFis. Thus the recommendation was worded accordingly. This recommendation was in fact reworded during the process of developing the recommendations to be in line with the fact that the evidence base is not different for enthesitis or dactylitis than for arthritis and axial disease. It should be noted that while apremilast has shown some efficacy on enthesitis, the Task Force felt that more data were needed than available at the time of the development of these recommendations. In general, physicians must apply good clinical judgement when faced with dactylitis/enthesitis towards appropriate use of bDMARDs without overusing them.

9. In patients with predominantly axial disease that is active and has insufficient response to NSAIDs, therapy with a bDMARD should be considered, which according to current practice is a TNFi.

This recommendation applies to the subgroup of patients with PsA who have predominant and active axial disease. Active disease here is usually defined in reference to a Bath Ankylosing Spondylitis Disease Activity Index above 4 points. In these patients, bDMARDs can be considered even if no csDMARDs have been tried, since csDMARDs have no proven efficacy in axial disease. ${ }^{96}$ Given the limited data on the efficacy of ustekinumab and the lack of data for secukinumab in patients with PsA with axial involvement, the experts held that TNFis would currently be the first choice of bDMARD in these patients (Ramiro S et al, Submitted to ARD 2015). Indeed, we do not currently have sufficient published data on efficacy of ustekinumab or secukinumab in patients with ankylosing spondylitis, and even less data on those patients with axial disease associated to psoriasis or PsA. ${ }^{97}$ This is also reflected in the current indication for these drugs (ustekinumab approved for PsA but not for axial spondyloarthritis). Thus, these agents may be useful but are recommended here only as alternatives, especially if TNFis fail or cannot be applied. No data were available to the Task Force on the effects of apremilast on axial disease.

10. In patients who fail to respond adequately to a bDMARD, switching to another bDMARD should be considered, including switching between TNFis.

This recommendation is derived from studies indicating a good efficacy of a second TNFi in PsA (Ramiro S et al, Submitted to ARD 2015). There is a lack of direct data of non-TNF inhibiting bDMARDs in such situations, but in randomised controlled trials of ustekinumab and secukinumab many patients (33-60\%) had previously been treated with TNFis, although their response rates were somewhat lower than seen in patients who had not previously experienced a bDMARD. ${ }^{84} 8788$ Thus, current therapies with a different molecular target do not appear to be more efficacious than another TNFi in this patient population by indirect judgement of the experts.

Switches are possible including for more than one switch and including intraclass or interclass switches (including switches from a bDMARD to a tsDMARD); it appears efficacy of third or fourth bDMARDs might be lower at the population level.

Although the Task Force discussed the issues of treatment tapering when the treatment target has been reached, it was felt that the available data were insufficient to develop a separate recommendation. ${ }^{98-102}$

As shown in table 1 , the levels of evidence were quite high for most of the items, although some are still mainly driven by expert opinion (particularly Recommendations 3 and 4). 
Interestingly with one exception, all items received a mean level of agreement that exceeded 9 of 10 .

\section{Research agenda}

As in 2012, a research agenda was developed/updated (table 2).

\section{DISCUSSION}

The updated recommendations for the pharmacological management of PsA presented here contain 5 overarching principles and 10 recommendations. As would be expected, many of the recommendations have remained largely unchanged compared

Table 2 Research agenda for PsA

Theme Research questions

Diagnosis Defining screening strategies for PsA among patients with psoriasis: is screening needed and if so, how and when?

Diagnosing PsA versus RA versus OA with concomitant psoriasis

Can we define criteria for early diagnosis of PsA?

Prognosis

Defining prognostic factors related to risk of progressive disease, structural damage and bad functional outcome in early (and established) PsA Predicting response to treatment (predicting response to NSAIDs, to cSDMARDs, to the different bDMARDs, to tsDMARDs)

Assessment of spinal disease: defining the similarities and differences with spondyloarthritis

Defining disease severity

Pathophysiology
Exploring juvenile PsA: is it different from adult-onset PsA?
Elucidation of the modes of action of ustekinumab and IL-17 inhibition
Identification of new therapeutic targets
Pathogenetic pathways leading to arthritis, dactylitis, enthesitis, axial disease and skin disease; similarities and differences
Genetics of PsA

Biomarkers Determining biomarkers related to damage, prognosis and treatment response

Treatment strategy Defining and evaluating the utility of tight control strategies in PsA

Assessing efficacy and safety of combinations of csDMARDs compared with csDMARD monotherapy (with and without low dose glucocorticoids)

Assessing efficacy and safety of combinations of csDMARDs with biologics compared with biologics monotherapy

Comparing efficacy and safety of methotrexate versus biological monotherapy versus their combination in early PsA

Evaluating the need for early treatment in PsA: who should be treated with csDMARDs? When to start treatment with DMARDs?

Switching and cycling between drugs

Outcomes Patient reported outcomes in PsA

Fatigue in PsA

Defining treatment targets

Defining (residual) active disease and low disease activity

Defining remission and predictors of remission and validating existing remission definitions

How does remission and especially sustained remission relate to long-term functional and structural outcomes and how does this compare to low disease activity or moderate/high disease activity?

What is an acceptable residual disease activity in PsA?

Is reaching remission more favourable in terms of outcomes (structure, function, etc) than reaching low disease activity or minimal disease activity?

Evaluating which components should be comprised in composite measures for PsA

How long can treatment with csDMARDs be delayed without structural penalty?

csDMARDs Comparative effectiveness research regarding csDMARDs alone and in comparison with bDMARDs

How efficacious is methotrexate in PsA?

Assessing efficacy and safety of combination therapy of csDMARDs

bDMARDs and Efficacy of combining csDMARDs with bDMARDs, compared with bDMARD monotherapy and to csDMARD monotherapy

tsDMARDs Comparison of apremilast with methotrexate and bDMARDs

Defining the best indication for bDMARDs, when to start?

Defining the optimal duration of biological therapy, including addressing bDMARD discontinuation

Assessing the possibility of maintenance therapy with lower doses of bDMARDs (dose reduction)

Is loss of good treatment state upon reduction or withdrawal of bDMARDs regainable upon reinstitution of the bDMARD?

Head-to-head trials of agents with different molecular targets in csDMARD-failures and TNFi-failures (including study of TNFi versus new biological agents)

Head-to-head trials of apremilast against methotrexate

Head-to-head trials of apremilast against biologicals

Structural data for apremilast

Data for the new drugs on enthesitis, dactylitis and axial disease

Comparative safety of bDMARDs in PsA

Is there a window of opportunity in PsA with induction therapy using bDMARDs?

Comparative effectiveness: head-to-head trials of apremilast versus secukinumab versus TNFis versus ustekinumab

Strategic trials aiming at remission or low disease activity

Drug tapering in remission

Systemic glucocorticoids Assessing the risk of skin flares related to systemic glucocorticoids and in particular at low doses

Assessing the benefit/risk ratio of long-term glucocorticoid therapy

Assessing the efficacy and toxicity of intramuscular glucocorticoids in PsA

Comorbidities

More knowledge on cardiovascular disease in PsA and links with disease activity

Assessing the risk and consequences of metabolic syndrome in PsA

Addressing tolerated consumption of alcohol in PsA in particular when treating by methotrexate

Imaging Defining the optimal use of radiographic scores

Evaluating the usefulness of MRI and ultrasonography, as well as developing scoring techniques for these imaging modalities for PsA

Which factors are related to bony appositions in PSA?

bDMARD, biological DMARD; csDMARDs, conventional synthetic DMARDs, such as methotrexate, sulfasalazine, or leflunomide; DMARD; DMARD, disease-modifying antirheumatic drug; NSAIDs, non-steroidal anti-inflammatory drugs; PSA, psoriatic arthritis; RA, rheumatoid arthritis; TNFi, tumour necrosis factor inhibitor; tsDMARD, targeted synthetic DMARD. 
with those provided in 2012. However, in 2012, patients with PsA had only TNFi available, once csDMARDs had failed, while meanwhile new bDMARDs, a bsDMARD and a tsDMARD have been, or are in the process of being approved for PsA, thus expanding the treatment armament importantly. Moreover, strategic trials had not been previously performed for PsA and this has changed meanwhile. Thus, the updated recommendations propose a new algorithm which integrates all these recent developments that include drugs with novel modes of action as well as novel strategic evidence and new data on already previously addressed agents or principles. These recommendations should provide physicians who treat patients with PsA with a practical approach to prescribing the most appropriate treatments for patients with PsA based on the most recent insights.

Beyond physicians, the EULAR recommendations are also aimed at patients with PsA so that they are informed about current treatment goals, strategies and opportunities. Importantly, patient representatives have also participated in the Task Force. It may, however, be useful to reformulate these recommendations into 'patient-friendly' wording to enhance their implementation. Moreover, other stakeholders, such a policy makers as well as representatives of hospital management and social security agencies are targeted to gain information on the latest therapeutic developments and approaches in the field.

The Task Force was convinced that modern therapy of PsA should be target-oriented and governed by a strategic treatment approach. Remission or at least low disease activity, if remission cannot be attained, was reaffirmed as the therapeutic goal. However, similarly to 2012, the literature review yielded sparse data regarding the natural history, prognosis, treatment targets and treatment strategies in PsA, in contrast to the situation in RA. ${ }^{55}{ }^{57}$ Moreover, the definition of remission remains to be validated in PsA. ${ }^{11} 2539$

The updated EULAR recommendations are an international document, designed and intended to serve a large array of stakeholders throughout Europe and beyond, although we are aware of the fact that not all agents mentioned here are universally available or accessible.

While we are aware that, in parallel, the Group for Research and Assessment of Psoriasis and Psoriatic Arthritis is also updating management recommendations, these recommendations may have a relatively prominent dermatology focus, ${ }^{103} 104$ while we very deliberately aimed and aim at developing recommendations that have a major focus on the musculoskeletal manifestations of PsA, since societies representing rheumatologists, other health professionals working in the field of rheumatology and patients with musculoskeletal disorders form EULAR's constituency.

These recommendations reflect the current state of evidence and opinions in the area of PsA pharmacological management. The 5 overarching principles and 10 practical recommendations have a high level of face validity and feasibility, and the development of a scientific agenda will guide future research. However, while many recommendations are based on high levels of evidence, some of them are solely based on expert opinion, implying that the research agenda is extensive and important.

In this respect it is important to bear in mind that, despite the evidence of their efficacy from randomised controlled trials, only expert opinion can currently define the place of the new drugs in the treatment algorithm. We are aware that this placement in the algorithm will be a topic of intense discussions in the rheumatology community. Indeed, some will contend that the Task Force has been too proactive and others will argue that it has been too limitative in terms of placement of the new drugs in the therapeutic algorithm or in terms of definitions of the target treatment population. However, the Task Force has very thoroughly considered overall efficacy (none of the new agents is numerically more efficacious than the TNFis), safety (some of the new agents indeed appear safer than TNFis) and costs, as far as comparatively available or known. Importantly, currently long-term experience on efficacy and safety exists for the TNFis, but not the new agents, and it is only such data that can elicit an amendment of these recommendations in the near future. Our aim is certainly to encourage further research and innovation in the field of rheumatic diseases, including accrual of efficacy and particularly safety data of new agents in registries and long-term extension trials. Thus, we feel that the proposed algorithm addresses all relevant issues related to an indirect 'comparison' of drugs, namely efficacy, safety, ease of use, costs and long-term experience.

It must also be borne in mind that the Task Force presents recommendations, not opposable guidelines, and thus the individual items reflect a majority view of many experts, including patient representatives, but at the same time provides sufficient leeway to the individual physician and national societies to consider a different approach than advocated here-this by no means would be 'wrong'. However, the very high level of agreement among the Task Force members across almost all recommendations supports their appropriateness and validity.

The Task Force was aware that some agents covered here were not yet approved for PsA by the European Medicine Agency at the times of the meeting and manuscript development. However, we based our assessments and decisions on the available and thoroughly evaluated and discussed literature and felt that the recommendations should include them in our aspiration to support physicians when taking treatment decisions now and in the near future.

Finally, as has been the case over the last decade, it is to be anticipated that new data on existing or new drugs or therapeutic strategies will emerge over the next few years and that some of the open questions as formulated here may be answered by then. Therefore, we will carefully observe the developments in the field and assume that an amendment of these recommendations may be needed in $2-3$ years' time.

\section{Author affiliations}

${ }^{1}$ Sorbonne Universités, UPMC Univ Paris 06, Institut Pierre Louis d'Epidémiologie et de Santé Publique, GRC-UPMC 08 (EEMOIS), Paris, France

${ }^{2}$ Department of rheumatology, AP-HP, Pitié Salpêtrière Hospital, Paris, France

${ }^{3}$ Division of Rheumatology, Department of Medicine 3, Medical University of Vienna, Vienna, Austria

${ }^{4}$ Second Department of Medicine, Hietzing Hospital, Vienna, Austria

${ }^{5}$ Department of Rheumatology, Leiden University Medical Centre, Leiden, The Netherlands

${ }^{6}$ EULAR, representing People with Arthritis/Rheumatism in Europe (PARE), London, UK

${ }^{7}$ Research Laboratory and Clinical Division of Rheumatology, Department of Internal Medicine, University of Genova, Viale Benedetto, Italy

${ }^{8}$ Medicine Faculty, Paris Descartes University, Paris, France

${ }^{9}$ Rheumatology B Department, APHP, Cochin Hospital, Paris, France

${ }^{10}$ Leeds NIHR Musculoskeletal Biomedical Research Unit, LTHT, Leeds, UK

${ }^{11}$ Leeds Institute of Rheumatic and Musculoskeletal Medicine, University of Leeds, Leeds, UK

${ }^{12}$ Department of Clinical Immunology \& Rheumatology, Amsterdam Rheumatology Center, Amsterdam, The Netherlands

${ }^{13}$ Atrium Medical Center, Heerlen, The Netherlands

${ }^{14}$ North Devon, UK

${ }^{15}$ Rheumazentrum Ruhrgebiet, Herne and Ruhr-Universität Bochum, Herne, Germany

${ }^{16}$ Department of Rheumatology and Clinical Immunology, Charité-University

Medicine Berlin, Germany

${ }^{17}$ Arthritis Unit, Department of Rheumatology, Hospital Clínic and IDIBAPS,

Barcelona, Spain

${ }^{18}$ Belgrade University School of Medicine, Belgrade, Serbia 
${ }^{19}$ Department of Rheumatology, St. Vincent's University Hospital and Conway Institute, University College Dublin, Dublin, Ireland

${ }^{20}$ Section of Rheumatology, Department of Clinical Sciences, Lund University, Lund, Sweden

${ }^{21}$ Sweden and School of Business, Engineering and Science, Halmstad University, Halmstad, Sweden

${ }^{22}$ Section of Musculoskeletal Disease, Leeds Institute of Molecular Medicine, University of Leeds, Leeds, UK

${ }^{23}$ Department of Rheumatology, Diakonhjemmet Hospital, Oslo, Norway

${ }^{24}$ Laboratory of Tissue Homeostasis and Disease, Skeletal Biology and Engineering

Research Center, KU Leuven, Belgium

${ }^{25}$ Division of Rheumatology, University Hospitals Leuven, Leuven, Belgium

${ }^{26}$ Department of Dermatology, University Hospital Münster, Münster, Germany

${ }^{27}$ A.DI.PSO. (Associazione per la Difesa degli Psoriasici)—PE.Pso.POF (Pan European Psoriasis Patients' Organization Forum), Rome, Italy

${ }^{28}$ Institute of Infection, Immunity and Inflammation, University of Glasgow, Glasgow,

${ }^{29}$ Rheumatology Department of Lucania, San Carlo Hospital of Potenza and Madonna delle Grazie Hospital of Matera, Potenza, Italy

${ }^{30}$ Institute and Clinic of Rheumatology Charles University Prague, Czech Republic

${ }^{31}$ Department of Internal Medicine 3, University of Erlangen-Nuremberg, Erlangen, Germany

${ }^{32}$ Department of Rheumatology, Campus Benjamin Franklin, Charité, Berlin, Germany

${ }^{33}$ Ghent University Hospital, Ghent, Belgium

${ }^{34}$ Centre for Arthritis and Rheumatic Disease, Dublin Academic Medical Centre,

St. Vincent's University Hospital, Dublin, Ireland.

${ }^{35}$ Schoen Klinik Hamburg, Rheumatology and Clinical Immunology, Hamburg, Germany

${ }^{36}$ Department of Rheumatology and Clinical Immunology, German Rheumatism Research Centre Berlin, Charité-University Medicine Berlin, Germany

Contributors All authors have contributed to this work and approved the final version.

Funding Supported by EULAR (grant CLI079).

Competing interests The authors declare receiving grant support and/or honoraria for consultations and/or for presentations as indicated: LG: Abbvie, Celgene, Chugai, Janssen, MSD, Novartis, Pfizer, Roche, Sanofi-Aventis, UCB; ISS: Amgen, Abbvie, Astra-Zeneca, Astro, BMS, Celgene, Glaxo, ILTOO, Janssen, Merck-Serono, MSD, Novartis-Sandoz, Pfizer, Roche-Chugai, Samsung, UCB; SR: no competing interests; MdW: AbbVie, BMS, Eli-Lilly, Roche; MC: Abbvie, Actelion, BMS, Boehringer, Celgene, Celltrion, Horizon, Mundipharm, Novartis, Pfizer; MD Abbvie, Lilly, Novartis, Pfizer, UCB; PE: Abbvie, BMS, MSD, Novartis-Sandoz, Pfizer, Roche-Chugai, Samsung, UCB; RL: AbbVie, Ablynx, Amgen, Astra-Zeneca, Bristol Myers Squibb, Celgene, Galapagos, Janssen (formerly Centocor), Glaxo-SmithKline, Novartis, Novo-Nordisk, Merck, Pfizer, Roche, Schering-Plough, TiGenix, UCB, Wyeth. Director of Rheumatology Consultancy BV; SO: AbbVie, Hospira, MSD; DA: Abbvie, BMS, Janssen, MSD, Pfizer, Roche; NB: Abbvie, BMS, Janssen, Pfizer; JB: Abbvie, Amgen, Bayer, BMS, Centocor, Celltrion, Chugai, Hospira, Janssen, MSD, Mundipharma, Novartis, Pfizer, Roche, Sanofi, and UCB; GB: AbbVie, Janssen, MSD, Novartis, Pfizer, UCB; JDC: Abbvie, Boehringer, Celgene, Janssen, MSD, Novartis, Novo-Nordisk, Pfizer, UCB; ND, KP: AbbVie, Amgen, BMS, Egis, Hospira, MSD, Pfizer, Roche, UCB; OF: Abbvie, Pfizer, Celgene, Janssen, UCB, Novartis, BMS, Lilly; EH: AbbVie, UCB; PH: Abbvie, Amgen, BMS, Celgene, Janssen, MSD, Pfizer, Roche; TKK: AbbVie, BMS, Boehringer Ingelheim, Celgene, Celltrion, Eli Lilly, Hospira, Merck-Serono, MSD, Novartis, Orion Pharma, Pfizer, Roche, Sandoz, UCB; RL: Abbvie, Boehringer Ingelheim, Bristol Myers Squibb, Merck, Pfizer, J\&J (Janssen), Celgene; TL: Abbvie, Astellas, Amgen, Biogen Idec, CERIES, Celgene, Clinuvel, Galderma, Janssen-Cilag, Lilly, La Roche Posay, MEDA Pharma, Mundipharma, Novartis, Pfizer, Symrise, Sandoz, Wolff; HM-O: Abbvie, Celgene, Janssen, MSD, Novartis, Pfizer, UCB; DM: AbbVie, Amgen, Bristol Myers Squibb, Celgene, Janssen, Novartis, Novo-Nordisk, Merck, Pfizer, Schering-Plough, UCB; IBM: Boehringer Ingelheim, Celgene, Novartis, Janssen, UCB, Abbvie, Pfizer, MSD, Amgen; 10: Abbvie, BMS, Celgene, Hospira, MSD, Mundipharma, Novartis, Pfizer, Roche, UCB; GS: Abbvie, BMS, Boehringer Ingelheim, Celgene, Chugai, Novartis, Pfizer, Roche, UCB; JS: Abbvie, Boehringer-Ingelheim, Janssen, Lilly, Merck, Novartis, Pfizer, UCB; FvdB: AbbVie, BMS, Celgene, Janssen, Merck, Novartis, Pfizer, UCB; DJV: AbbVie, Actelion, BMS, Celgene, Janssen, MSD, Pfizer, Roche, UCB; JW: AbbVie, Ablynx, Astra-Zeneca, BMS, Celgene, Janssen, Novartis, MSD, Pfizer, Roche, UCB; AZ: AbbVie, BMS, Celltrion, Hexal, Hospira, MSD, Pfizer, Roche, Sanofi, UCB; DvdH: AbbVie, Amgen, Astellas, AstraZeneca, Augurex, BMS, Boehringer Ingelheim, Celgene, Centocor, Chugai, Covagen, Daiichi, Eli-Lilly, Galapagos, GSK, Janssen Biologics, Merck, Novartis, Novo-Nordisk, Otsuka, Pfizer, Roche, Sanofi-Aventis, UCB, Vertex. Director of Imaging Rheumatology BV.

Provenance and peer review Not commissioned; externally peer reviewed.

\section{REFERENCES}

1 Michelsen B, Fiane R, Diamantopoulos AP, et al. A comparison of disease burden in rheumatoid arthritis, psoriatic arthritis and axial spondyloarthritis. PLOS ONE 2015; 10:e0123582.

2 Strand V, Sharp V, Koenig AS, et al. Comparison of health-related quality of life in rheumatoid arthritis, psoriatic arthritis and psoriasis and effects of etanercept treatment. Ann Rheum Dis 2012;71:1143-50.

3 Smolen JS, van der Heijde D, Machold KP, et al. Proposal for a new nomenclature of disease-modifying antirheumatic drugs. Ann Rheum Dis 2014;73:3-5.

4 Ash Z, Gaujoux-Viala C, Gossec L, et al. A systematic literature review of drug therapies for the treatment of psoriatic arthritis: current evidence and meta-analysis informing the EULAR recommendations for the management of psoriatic arthritis. Ann Rheum Dis 2012;71:319-26.

5 FitzGerald 0 , Haroon M, Giles JT, et al. Concepts of pathogenesis in psoriatic arthritis: genotype determines clinical phenotype. Arthritis Res Ther 2015; $17: 115$.

6 Siegel EL, Orbai A-M, Ritchlin CT. Targeting extra-articular manifestations in PsA a closer look at enthesitis and dactylitis. Curr Opin Rheumatol 2015;27:111-17.

7 Moll JM, Wright V. Psoriatic arthritis. Semin Arthritis Rheum 1973;3:55-78.

8 Gossec L, Smolen JS, Gaujoux-Viala C, et al. European League Against Rheumatism recommendations for the management of psoriatic arthritis with pharmacological therapies. Ann Rheum Dis 2012;71:4-12.

9 Paccou J, Wendling D. Current treatment of psoriatic arthritis: update based on a systematic literature review to establish French Society for Rheumatology (SFR) recommendations for managing spondyloarthritis. Jt Bone Spine 2015;82:80-5.

10 Coates LC, Navarro-Coy N, Brown SR, et al. The TICOPA protocol (Tlght COntrol of Psoriatic Arthritis): a randomised controlled trial to compare intensive management versus standard care in early psoriatic arthritis. BMC Musculoskelet Disord 2013;14:101.

11 Smolen JS, Braun J, Dougados M, et al. Treating spondyloarthritis, including ankylosing spondylitis and psoriatic arthritis, to target: recommendations of an international task force. Ann Rheum Dis 2014:73:6-16.

12 Schoels MM, Braun J, Dougados $M$, et al. Treating axial and peripheral spondyloarthritis, including psoriatic arthritis, to target: results of a systematic literature search to support an international treat-to-target recommendation in spondyloarthritis. Ann Rheum Dis 2014;73:238-42.

13 van der Heijde D, Aletaha D, Carmona L, et al. 2014 Update of the EULAR standardised operating procedures for EULAR-endorsed recommendations. Ann Rheum Dis 2015;74:8-13.

14 Ramiro S, Smolen JS, Landewé R, et al. Pharmacological treatment of psoriatic arthritis: a systematic literature review for the 2015 update of the EULAR recommendations for the management of psoriatic arthritis. Ann Rheum Dis 2016:75:490-8.

15 Guyatt $\mathrm{GH}$, Oxman AD, Kunz R, et al. Going from evidence to recommendations. BMJ 2008;336:1049-51.

16 OCEBM Levels of Evidence Working Group. The Oxford Levels of Evidence. Oxford Centre for Evidence-Based Medicine. http://www.cebm.net/index.aspx?0=5653

17 Guyatt $\mathrm{GH}$, Oxman $A D$, Kunz R, et al. Incorporating considerations of resources use into grading recommendations. BMJ 2008;336:1170-3.

18 Ogdie A, Schwartzman S, Husni ME. Recognizing and managing comorbidities in psoriatic arthritis. Curr Opin Rheumatol 2015;27:118-26.

19 Di Minno MND, Ambrosino P, Lupoli R, et al. Cardiovascular risk markers in patients with psoriatic arthritis: a meta-analysis of literature studies. Ann Med 2015:47:346-53.

20 Smolen JS, Breedveld FC, Burmester GR, et al. Treating rheumatoid arthritis to target: 2014 update of the recommendations of an international task force. Ann Rheum Dis 2016:75:3-15.

21 Stoffer MA, Schoels MM, Smolen JS, et al. Evidence for treating rheumatoid arthritis to target: results of a systematic literature search update. Ann Rheum Dis 2016;75:16-22.

22 Jadon DR, Shaddick G, Tillett W, et al. Psoriatic Arthritis mutilans: characteristics and natural radiographic history. J Rheumatol 2015;42:1169-76.

23 Armstrong AW, Gelfand JM, Garg A. Outcomes research in psoriasis and psoriatic arthritis using large databases and research networks: a report from the GRAPPA 2013 Annual Meeting. J Rheumatol 2014;41:1233-6.

24 Van den Bosch F, Kavanaugh A, Kron M, et al. Clinical remission in patients with active psoriatic arthritis treated with adalimumab and correlations in joint and skin manifestations. J Rheumatol 2015:42:952-9.

25 Schoels M, Aletaha D, Alasti F, et al. Disease activity in psoriatic arthritis (PsA): defining remission and treatment success using the DAPSA score. Ann Rheum Dis 2015. Published Online First 12 Aug 2015. doi: 10.1136/annrheumdis-2015207507.

26 Bond SJ, Farewell VT, Schentag CT, et al. Predictors for radiological damage in psoriatic arthritis: results from a single centre. Ann Rheum Dis 2007:66:370-6.

27 Lindqvist URC, Alenius G-M, Husmark T, et al. The Swedish early psoriatic arthritis register-2-year followup: a comparison with early rheumatoid arthritis. I Rheumatol 2008;35:668-73. 
28 McHugh NJ, Balachrishnan C, Jones SM. Progression of peripheral joint disease in psoriatic arthritis: a 5-yr prospective study. Rheumatology 2003:42:778-83.

29 Gladman DD, Farewell VT, Nadeau C. Clinical indicators of progression in psoriatic arthritis: multivariate relative risk model. J Rheumatol 1995;22:675-9.

30 Siannis F, Farewell VT, Cook RJ, et al. Clinical and radiological damage in psoriatic arthritis. Ann Rheum Dis 2006;65:478-81.

31 Gossec L, de Wit M, Kiltz U, et al. A patient-derived and patient-reported outcome measure for assessing psoriatic arthritis: elaboration and preliminary validation of the Psoriatic Arthritis Impact of Disease (PsAID) questionnaire, a 13-country EULAR initiative. Ann Rheum Dis 2014;73:1012-19.

32 Cantini F, Niccoli L, Cassarà E, et al. Sustained maintenance of clinical remission after adalimumab dose reduction in patients with early psoriatic arthritis: a long-term follow-up study. Biologics 2012;6:201-6.

33 Cantini F, Niccoli L, Nannini C, et al. Criteria, frequency, and duration of clinical remission in psoriatic arthritis patients with peripheral involvement requiring second-line drugs. J Rheumatol Supp/ 2009;83:78-80.

34 Cantini F, Niccoli L, Nannini C, et al. Frequency and duration of clinical remission in patients with peripheral psoriatic arthritis requiring second-line drugs. Rheumatology 2008;47:872-6.

35 Iervolino S, Di Minno MND, Peluso R, et al. Predictors of early minimal disease activity in patients with psoriatic arthritis treated with tumor necrosis factor- $\alpha$ blockers. J Rheumatol 2012;39:568-73.

36 Felson DT, Smolen JS, Wells G, et al. American College of Rheumatology/European League against Rheumatism provisional definition of remission in rheumatoid arthritis for clinical trials. Ann Rheum Dis 2011;70:404-13.

37 Salaffi F, Ciapetti A, Carotti M, et al. Disease activity in psoriatic arthritis: comparison of the discriminative capacity and construct validity of six composite indices in a real world. BioMed Res Int 2014;2014:528105.

38 Helliwell PS, FitzGerald O, Fransen J. Composite disease activity and responder indices for psoriatic arthritis: a report from the GRAPPA 2013 meeting on development of cutoffs for both disease activity states and response. J Rheumatol 2014:41:1212-17.

39 Coates LC, Helliwell PS. Validation of minimal disease activity criteria for psoriatic arthritis using interventional trial data. Arthritis Care Res 2010;62:965-9.

40 Coates LC, Cook R, Lee K-A, et al. Frequency, predictors, and prognosis of sustained minimal disease activity in an observational psoriatic arthritis cohort. Arthritis Care Res 2010;62:970-6.

41 Coates LC, Fransen J, Helliwell PS. Defining minimal disease activity in psoriatic arthritis: a proposed objective target for treatment. Ann Rheum Dis 2010;69:48-53.

42 Mease PJ, Heckaman M, Kary S, et al. Application and modifications of minimal disease activity measures for patients with psoriatic arthritis treated with adalimumab: subanalyses of ADEPT. I Rheumatol 2013;40:647-52.

43 Haddad A, Thavaneswaran A, Ruiz-Arruza I, et al. Minimal disease activity and anti-tumor necrosis factor therapy in psoriatic arthritis. Arthritis Care Res 2015;67:842-7.

44 Coates LC, Moverley AR, McParland L, et al. Effect of tight control of inflammation in early psoriatic arthritis (TICOPA): a UK multicentre, open-label, randomised controlled trial. Lancet 2015 doi: 10.1016/50140-6736(15)00347-5. [Epub ahead of print 30 Sept 2015].

45 Tillett W, Eder L, Goel N, et al. Enhanced patient involvement and the need to revise the core set-report from the psoriatic arthritis working group at OMERACT 2014. J Rheumatol 2015;42:2198-203.

46 Machado PM, Raychaudhuri SP. Disease activity measurements and monitoring in psoriatic arthritis and axial spondyloarthritis. Best Pract Res Clin Rheumatol 2014;28:711-28.

47 Healy PJ, Helliwell PS. Measuring clinical enthesitis in psoriatic arthritis: assessment of existing measures and development of an instrument specific to psoriatic arthritis. Arthritis Rheum 2008:59:686-91.

48 Nell-Duxneuner VP, Stamm TA, Machold KP, et al. Evaluation of the appropriateness of composite disease activity measures for assessment of psoriatic arthritis. Ann Rheum Dis 2010;69:546-9.

49 Gladman DD, Landewé R, McHugh NJ, et al. Composite measures in psoriatic arthritis: GRAPPA 2008. I Rheumatol 2010;37:453-61.

50 Leeb BF, Andel I, Sautner J, et al. The Disease Activity Score in 28 joints in rheumatoid arthritis and psoriatic arthritis patients. Arthritis Rheum 2007;57:256-60.

51 Mumtaz A, Gallagher P, Kirby B, et al. Development of a preliminary composite disease activity index in psoriatic arthritis. Ann Rheum Dis 2011;70:272-7.

52 Schoels M, Aletaha D, Funovits J, et al. Application of the DAREA/DAPSA score for assessment of disease activity in psoriatic arthritis. Ann Rheum Dis 2010;69:1441-7

53 Helliwell PS, FitzGerald O, Fransen J, et al. The development of candidate composite disease activity and responder indices for psoriatic arthritis (GRACE project). Ann Rheum Dis 2013;72:986-91.

54 Gladman DD, Chandran V. Review of clinical registries of psoriatic arthritis: lessons learned?: value for the future? Curr Rheumatol Rep 2011;13:346-52.
55 Cresswell L, Chandran V, Farewell VT, et al. Inflammation in an individual joint predicts damage to that joint in psoriatic arthritis. Ann Rheum Dis 2011;70:305-8.

56 Brockbank JE, Stein M, Schentag CT, et al. Dactylitis in psoriatic arthritis: a marker for disease severity? Ann Rheum Dis 2005;64:188-90.

57 Simon $\mathrm{P}$, Pfoehler $\mathrm{C}$, Bergner $\mathrm{R}$, et al. Swollen joint count in psoriatic arthritis is associated with progressive radiological damage in hands and feet. Clin Exp Rheumatol 2012:30:45-50

58 Gladman DD, Mease PJ, Choy EHS, et al. Risk factors for radiographic progression in psoriatic arthritis: subanalysis of the randomized controlled trial ADEPT. Arthritis Res Ther 2010;12:R113.

59 Kirkham B, de Vlam K, Li W, et al. Early treatment of psoriatic arthritis is associated with improved patient-reported outcomes: findings from the etanercept PRESTA trial. Clin Exp Rheumatol 2015;33:11-19.

60 Theander E, Husmark T, Alenius G-M, et al. Early psoriatic arthritis: short symptom duration, male gender and preserved physical functioning at presentation predict favourable outcome at 5-year follow-up. Results from the Swedish Early Psoriatic Arthritis Register (SwePsA). Ann Rheum Dis 2014;73:407-13.

61 Gladman DD, Thavaneswaran A, Chandran V, et al. Do patients with psoriatic arthritis who present early fare better than those presenting later in the disease? Ann Rheum Dis 2011;70:2152-4.

62 Haroon M, Gallagher P, FitzGerald O. Diagnostic delay of more than 6 months contributes to poor radiographic and functional outcome in psoriatic arthritis. Ann Rheum Dis 2015;74:1045-50.

63 Tillett W, Jadon D, Shaddick G, et al. Smoking and delay to diagnosis are associated with poorer functional outcome in psoriatic arthritis. Ann Rheum Dis 2013;72:1358-61.

64 Kingsley GH, Kowalczyk A, Taylor $\mathrm{H}$, et al. A randomized placebo-controlled trial of methotrexate in psoriatic arthritis. Rheumatology 2012;51:1368-77.

65 Lie E, van der Heijde D, Uhlig T, et al. Effectiveness and retention rates of methotrexate in psoriatic arthritis in comparison with methotrexate-treated patients with rheumatoid arthritis. Ann Rheum Dis 2010:69:671-6.

66 Helliwell PS, Taylor WJ, CASPAR Study Group. Treatment of psoriatic arthritis and rheumatoid arthritis with disease modifying drugs-comparison of drugs and adverse reactions. J Rheumatol 2008:35:472-6.

67 Curtis JR, Beukelman T, Onofrei A, et al. Elevated liver enzyme tests among patients with rheumatoid arthritis or psoriatic arthritis treated with methotrexate and/or leflunomide. Ann Rheum Dis 2010;69:43-7.

68 Schmitt J, Rosumeck S, Thomaschewski G, et al. Efficacy and safety of systemic treatments for moderate-to-severe psoriasis: meta-analysis of randomized controlled trials. Br I Dermatol 2014;170:274-303.

69 Fraser AD, van Kuijk AWR, Westhovens $R$, et al. A randomised, double blind, placebo controlled, multicentre trial of combination therapy with methotrexate plus ciclosporin in patients with active psoriatic arthritis. Ann Rheum Dis 2005;64:859-64.

70 Eder L, Chandran V, Ueng J, et al. Predictors of response to intra-articular steroid injection in psoriatic arthritis. Rheumatology 2010;49:1367-73.

71 Gaujoux-Viala C, Gossec L. When and for how long should glucocorticoids be used in rheumatoid arthritis? International guidelines and recommendations. Ann N Y Acad Sci 2014;1318:32-40.

72 Hoes JN, Jacobs JWG, Verstappen SMM, et al. Van der Heijden GJMG. Adverse events of low- to medium-dose oral glucocorticoids in inflammatory diseases: a meta-analysis. Ann Rheum Dis 2009;68:1833-8.

73 Eder L, Thavaneswaran A, Chandran V, et al. Tumour necrosis factor $\alpha$ blockers are more effective than methotrexate in the inhibition of radiographic joint damage progression among patients with psoriatic arthritis. Ann Rheum Dis 2014:73:1007-11.

74 Glintborg B, Østergaard M, Dreyer L, et al. Treatment response, drug survival, and predictors thereof in 764 patients with psoriatic arthritis treated with anti-tumor necrosis factor $\alpha$ therapy: results from the nationwide Danish DANBIO registry. Arthritis Rheum 2011;63:382-90.

75 Kristensen LE, Gülfe A, Saxne T, et al. Efficacy and tolerability of anti-tumour necrosis factor therapy in psoriatic arthritis patients: results from the South Swedish Arthritis Treatment Group register. Ann Rheum Dis 2008;67:364-9.

76 Park W, Hrycaj P, Jeka S, et al. A randomised, double-blind, multicentre, parallel-group, prospective study comparing the pharmacokinetics, safety, and efficacy of CT-P13 and innovator infliximab in patients with ankylosing spondylitis: the PLANETAS study. Ann Rheum Dis 2013;72:1605-12.

77 Fagerli KM, Lie E, van der Heijde D, et al. The role of methotrexate co-medication in TNF-inhibitor treatment in patients with psoriatic arthritis: results from 440 patients included in the NOR-DMARD study. Ann Rheum Dis 2014;73:132-7.

78 Baranauskaite A, Raffayová $\mathrm{H}$, Kungurov NV, et al. Infliximab plus methotrexate is superior to methotrexate alone in the treatment of psoriatic arthritis in methotrexate-naive patients: the RESPOND study. Ann Rheum Dis 2012;71: $541-8$

79 Palazzi C, D'Angelo S, Leccese P, et al. Safety of anti-tumor necrosis factor agents in psoriatic arthritis—an update. Expert Opin Drug Saf 2014;13:191-6. 
80 Gottlieb A, Menter A, Mendelsohn A, et al. Ustekinumab, a human interleukin 12/23 monoclonal antibody, for psoriatic arthritis: randomised, double-blind, placebo-controlled, crossover trial. Lancet 2009;373:633-40.

81 Kavanaugh A, Ritchlin C, Rahman P, et al. Ustekinumab, an anti-IL-12/23 p40 monoclonal antibody, inhibits radiographic progression in patients with active psoriatic arthritis: results of an integrated analysis of radiographic data from the phase 3, multicentre, randomised, double-blind, placebo-controlled PSUMMIT-1 and PSUMMIT-2 trials. Ann Rheum Dis 2014;73:1000-6.

82 Kavanaugh A, Menter A, Mendelsohn A, et al. Effect of ustekinumab on physical function and health-related quality of life in patients with psoriatic arthritis: a randomized, placebo-controlled, phase II trial. Curr Med Res Opin 2010;26: 2385-92.

83 McInnes IB, Kavanaugh A, Gottlieb AB, et al. Efficacy and safety of ustekinumab in patients with active psoriatic arthritis: 1 year results of the phase 3, multicentre, double-blind, placebo-controlled PSUMMIT 1 trial. Lancet 2013;382:780-9.

84 Ritchlin C, Rahman P, Kavanaugh A, et al. Efficacy and safety of the anti-IL-12/23 p40 monoclonal antibody, ustekinumab, in patients with active psoriatic arthritis despite conventional non-biological and biological anti-tumour necrosis factor therapy: 6-month and 1-year results of the phase 3, multicentre, double-blind, placebo-controlled, randomised PSUMMIT 2 trial. Ann Rheum Dis 2014;73:990-9.

85 Sofen H, Smith S, Matheson RT, et al. Guselkumab (an IL-23-specific mAb) demonstrates clinical and molecular response in patients with moderate-to-severe psoriasis. J Allergy Clin Immunol 2014;133:1032-40.

86 Kopp T, Riedl E, Bangert C, et al. Clinical improvement in psoriasis with specific targeting of interleukin-23. Nature 2015;521:222-6.

87 Mclnnes IB, Sieper J, Braun J, et al. Efficacy and safety of secukinumab, a fully human anti-interleukin-17A monoclonal antibody, in patients with moderate-to-severe psoriatic arthritis: a 24-week, randomised, double-blind, placebo-controlled, phase II proof-of-concept trial. Ann Rheum Dis 2014;73:349-56.

88 Mclnnes IB, Mease PJ, Kirkham B, et al. Secukinumab, a human anti-interleukin-17A monoclonal antibody, in patients with psoriatic arthritis (FUTURE 2): a randomised, double-blind, placebo-controlled, phase 3 trial. Lancet 2015;386:1137-46.

89 Helliwell P, Coates L. Interleukin-17 inhibition in psoriatic arthritis. Lancet 2015:386:1114-16.

90 Mease PJ, Genovese MC, Greenwald MW, et al. Brodalumab, an anti-IL17RA monoclonal antibody, in psoriatic arthritis. N Eng/ J Med 2014;370:2295-306.
91 Kavanaugh A, Mease PJ, Gomez-Reino JJ, et al. Treatment of psoriatic arthritis in a phase 3 randomised, placebo-controlled trial with apremilast, an oral phosphodiesterase 4 inhibitor. Ann Rheum Dis 2014;73:1020-6.

92 Schett G, Wollenhaupt J, Papp K, et al. Oral apremilast in the treatment of active psoriatic arthritis: results of a multicenter, randomized, double-blind, placebo-controlled study. Arthritis Rheum 2012;64:3156-67.

93 Strand V, Schett G, Hu C, et al. Patient-reported Health-related Quality of Life with apremilast for psoriatic arthritis: a phase II, randomized, controlled study. J Rheumatol 2013;40:1158-65.

94 Orbai A-M, Weitz J, Siegel EL, et al. Systematic review of treatment effectiveness and outcome measures for enthesitis in psoriatic arthritis. J Rheumatol 2014:41:2290-4.

95 Rose S, Toloza S, Bautista-Molano W, et al. GRAPPA Dactylitis Study Group. Comprehensive treatment of dactylitis in psoriatic arthritis. J Rheumatol 2014;41:2295-300.

96 van der Heijde D, Sieper J, Maksymowych WP, et al. 2010 Update of the international ASAS recommendations for the use of anti-TNF agents in patients with axial spondyloarthritis. Ann Rheum Dis 2011;70:905-8.

97 Baeten D, Baraliakos X, Braun J, et al. Anti-interleukin-17A monoclonal antibody secukinumab in treatment of ankylosing spondylitis: a randomised, double-blind, placebo-controlled trial. Lancet 2013;382:1705-13.

98 Moverley A, Coates L, Marzo-Ortega $\mathrm{H}$, et al. A feasibility study for a randomised controlled trial of treatment withdrawal in psoriatic arthritis (REmoval of treatment for patients in REmission in psoriatic ArThritis (RETREAT (F)). Clin Rheumatol 2015;34:1407-12.

99 Janta I, Martínez-Estupiñán L, Valor L, et al. Comparison between full and tapered dosages of biologic therapies in psoriatic arthritis patients: clinical and ultrasound assessment. Clin Rheumatol 2015;34:935-42.

100 Araujo EG, Finzel S, Englbrecht $M$, et al. High incidence of disease recurrence after discontinuation of disease-modifying antirheumatic drug treatment in patients with psoriatic arthritis in remission. Ann Rheum Dis 2015;74:655-60.

101 Mease P. Is reduction or discontinuation of therapy an acceptable possibility in psoriatic arthritis? Clin Exp Rheumatol 2013;31(4 Suppl 78):S59-62.

102 Chimenti MS, Esposito M, Giunta A, et al. Remission of psoriatic arthritis after etanercept discontinuation: analysis of patients' clinical characteristics leading to disease relapse. Int J Immunopathol Pharmacol 2013;26:833-8.

103 Coates LC, Ritchlin CT, Kavanaugh AF. GRAPPA treatment recommendations: an update from the GRAPPA 2013 Annual Meeting. J Rheumatol 2014;41:1237-9.

104 Ritchlin CT, Kavanaugh A, Gladman DD, et al. Treatment recommendations for psoriatic arthritis. Ann Rheum Dis 2009;68:1387-94. 